1655 METAL EXPOSURE IMPACTING BONE, HEMATOPOIESIS, AND REPRODUCTIVE FUNCTIONS AND EXPOSURE MONITORING

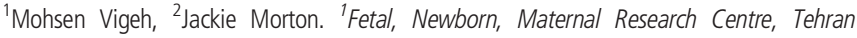
University of Medical Sciences, Tehran, Iran; ${ }^{2}$ Health and Safety Executive, Harpur Hill, Buxton, SK17 9JN, UK

10.1136/oemed-2018-ICOHabstracts. 1444

Aim of special session To provide current knowledge on toxic effect of metal exposure and organ toxicity.

\section{5a REPRODUCTIVE TOXICITY OF METALS: CRITICAL TIME OF PRENATAL EXPOSURE}

1,2,3 Mohsen Vigeh, ${ }^{2}$ Kazuhito Yokoyama, ${ }^{2}$ Takehisa Matsukawa, ${ }^{1}$ Katsumi Ohtani. ${ }^{1}$ Fetal, Newborn, Maternal Research Centre, Tehran University of Medical Sciences, Tehran, Iran; ${ }^{2}$ Occupational Epidemiology, National Institute of Occupational Safety and Health, Kawasaki, Japan; ${ }^{3}$ Department of Epidemiology and Environmental Health, Juntendo University Faculty of Medicine, Tokyo, Japan

\subsection{6/oemed-2018-ICOHabstracts. 1445}

Introduction Pregnancy is a unique period of women life with an increased sensitivity to toxicants, such as heavy metals. Recently, exposure to potentially toxic metals decreased sharply in both general population and workers but, chronic exposure to low-levels remained a public health problems.

Methods We have conducted longitudinal studies to estimate effects of prenatal metal exposure on various pregnancy outcomes. Maternal whole blood (taken in the first, second, and third trimester of pregnancy) and umbilical cord blood samples were collected for blood metals measurement using ICPMS devices. We collected participants' characteristics information and past reproductive and medical history using a structured questionnaire. Data about various pregnancy outcomes gathered during pregnancy and at the delivery.

Result We found blood metals at the early stage of pregnancy had more significant effects on pregnancy outcomes, such as low birth weight, preterm labour, preterm rupture of the membranes, and pregnancy induced-hypertension than the subsequence trimesters, or in the umbilical cord blood. In addition, the study revealed a high rate passing metals from placenta, which could increase metals level up to twice in fetal site than the maternal blood.

Discussion The early gestation metal exposure can be induce several adverse pregnancy outcomes. Therefore, the exposure protection or screening programs for the high-level exposure female workers, should be considered before pregnancy or as early as possible, because later intervention may not prevent adverse effects.

\section{$1655 \mathrm{~b}$ THE USEFULNESS OF BIOLOGICAL MONITORING IN DETERMINING MANGANESE EXPOSURE IN THE WORKPLACE}

J Morton, H Beattie, E Leese, K Jones. Health and Safety Executive, Harpur Hill, Buxton, SK17 9JN, UK

\subsection{6/oemed-2018-ICOHabstracts. 1446}

Introduction Exposure to manganese in the workplace is an occupational health concern, it is known that even at relatively low levels of exposure subtle neurological effects have been observed in workers (Baker, et al., 2014).

Various biomarkers of exposure have been explored as a way to quantitatively estimate exposure to manganese, however, identification of a biomarker for manganese exposure has been elusive.

This study involves a comprehensive collection of samples, conducted in several workplaces, in order to try and evaluate the usefulness of biological samples for in determining manganese exposures. Using optimised analytical instrumentation with low detection limits, the novel biological matrix exhaled breath condensate (EBC), as well as urine and air samples were collected.

Methods Three sites were visited each for a week to collect urine, EBC and air samples. A full occupational hygiene assessment was also undertaken at each site. At the first site urine samples were collected pre and post shift each day for a week, EBC samples were collected pre on a Monday morning and post on a Thursday afternoon. Air samples were collected Monday and Thursdays. At the other sites EBC and air samples were collected daily. The samples were analysed by ICPMS. Other relevant elements such as nickel, iron, chromium and zinc were also determined.

Results The biomonitoring results from the first manganese welding site showed that there were higher manganese concentrations in the EBC and urine in grinders and welders compared to burners and office staff. There was not a good correlation between the air and biomonitoring samples and this will be more comprehensively studied in the next two site visits to be undertaken in 2017.

Discussion This study suggests that biomonitoring for manganese may be useful in certain workplace scenarios and this will be explored further.

\section{BIOLOGICAL EFFECTS OF COPPER AND ZINC CONTAINING WELDING FUMES AFTER CONTROLLED EXPOSURE OF HUMANS}

${ }^{1} \mathrm{P}$ Brand, ${ }^{2} \mathrm{M}$ Gube, ${ }^{1} \mathrm{~A}$ Markert, ${ }^{1} \mathrm{R}$ Baumann, ${ }^{3} \mathrm{~B}$ Gerhards, ${ }^{1} \mathrm{~T}$ Kraus. ${ }^{1}$ Institute for Occupational and Social Medicine, RWTH Aachen University; ${ }^{2}$ Public Health Department of City Region Aachen; ${ }^{3}$ SF - Welding and Joining Institute, RWTH Aachen University

\subsection{6/oemed-2018-ICOHabstracts. 1447}

Introduction Copper and zinc containing welding fumes are suspected to induce inflammatory reactions, which, in humans, may result in metal fume fever. In a series of studies, early reactions of such welding fumes were investigated.

Methods Exposures were performed in the Aachen Workplace Simulation Lab. 15 healthy male subjects were exposed for 6 hours to average welding fume mass concentrations up to $2.5 \mathrm{mg} \mathrm{m}-3$. Welding fumes resulted from Metal-Inert-Gas brazing of zinc coated steel using copper welding wire or resistance spot welding of zinc-coated steel. Inflammatory markers were measured in the blood or in nasal secretions prior to exposure, directly after or 24-29 hours after exposure.

Results The main results of these studies were:

- exposure to zinc and copper containing welding fumes lead to an asymptomatic inflammatory reaction as shown by an increase of blood C-reactive-Protein (CRP). 